\title{
Gene editing to investigate the role of conceptus factors in the establishment of pregnancy in the pig
}

\author{
Rodney D Geisert, Ashley E Meyer, Caroline A Pfeiffer, Destiny N Johns, Kiho Lee, \\ Kevin D Wells, Thomas E Spencer and Randall S Prather \\ Division of Animal Sciences, University of Missouri, Columbia, Missouri, USA \\ Correspondence should be addressed to R D Geisert; Email: geisertr@missouri.edu
}

\begin{abstract}
Development of viviparity in mammals requires that the placenta evolves as an intermediate interface between the fetus and maternal uterus. In addition to the retention of the fetus and secretion of nutrients to support growth and development to term, it is essential that viviparous species modify or inhibit the maternal immune system from recognizing the semi-allogeneic fetus. Following blastocyst hatching from its zona pellucida, trophoblast differentiation provides the initial communication to the maternal endometrium to regulate maintenance of progesterone production from the corpus luteum and biological pathways in uterine and conceptus development necessary in the establishment and maintenance of pregnancy. Many conceptus factors have been proposed to serve in the establishment and maintenance of pregnancy. CRISPR-Cas9 gene-editing technology provides a specific and efficient method to generate animal models to perform loss-of-function studies to investigate the role of specific conceptus factors. The utilization of CRISPR-Cas9 gene editing has provided a direct approach to investigate the specific role of conceptus factors in the development and establishment of pregnancy in the pig. This technology has helped address a number of questions concerning peri-implantation development and has altered our understanding of maternal recognition and maintenance of pregnancy in the pig. Reproduction (2021) 161 R79-R88
\end{abstract}

\section{Introduction}

In contrast to oviparous and ovoviviparous species which rely on an adequate supply of yolk to support embryo development, viviparity in mammals evolved through the differentiation and adaptation of the placenta to function as a conduit for interplay between the semi-allogeneic fetus with the maternal endometrium. Although the type of placentation (invasive to superficial attachment) varies among mammalian species, an essential component for the development of viviparity first required retention of the embryo within the uterus for an extended period of time. This required that mechanisms evolve to ensure a source (corpus luteum and/or placenta) of progesterone was supplied throughout gestation. Adaptation of the uterus to respond to progesterone secreted by the maternal corpus luteum $(\mathrm{CL})$ was not only essential to block strong coordinated myometrial contractions but also to stimulate secretions from the endometrial surface epithelium and uterine glands necessary for conceptus and placental growth and development until birth. The placenta provides the interface for maternal and fetal gas, mineral and nutrient exchange throughout pregnancy. In addition to the retention of the embryo in utero and provision of nutrient support to the developing conceptus, it was essential that viviparity evolves pathways to modify or inhibit the maternal immune system from recognizing the semi-allogeneic fetus.

Blastocyst development, which is conserved across most viviparous mammals, is the direct prelude to the placental formation and immediate interaction with the maternal endometrial surface (Telugu \& Pence 2021). Depending upon the species, blastocyst hatching from its zona pellucida leads to the attachment of the trophoblast to the endometrial surface, followed by either continued growth and expansion throughout the uterine lumen (ruminants, pig, horse) or invasion through the surface epithelium to implant within the endometrium (rodents, primates, humans). Attachment of the trophoblast to the maternal endometrial surface initiates closely regulated biological processes in uterine and conceptus development necessary for the establishment and maintenance of pregnancy in viviparous mammalian species (Amoroso 1952, Perry 1981, Spencer \& Bazer 2004, Roberts et al. 2016).

Previous research has investigated the fundamental roles of conceptus- and uterine-derived factors to understand how the conceptus interacts with the maternal uterus to establish pregnancy and to develop strategies to improve placental and fetal growth for the overall health and survivability of the fetus before and after birth. The interaction of the conceptus/placenta 
with the maternal uterus is complex and involves a multitude of diverse factors and biological pathways which have been the subject of many excellent reviews across numerous species (Geisert \& Bazer 2015). Numerous research studies have focused on the role(s) of a specific conceptus factor in the establishment and maintenance of pregnancy. Attempts to evaluate the role of many conceptus-secreted factors in utero involved the utilization of inhibitors that were available at the time. However, in vivo application of inhibitors or antagonists to study reproduction has broad effects on the embryo, uterus and maternal system. Therefore, it is difficult to know if the conceptus-secreted factor is truly essential for the establishment and maintenance of pregnancy given that there can be redundancy with other conceptus or conceptus-stimulated endometrial factors that serve to regulate the same biological pathways. In this regard, the development of the CRISPR-Cas9 gene-editing technology in pigs and other livestock species provides a specific and efficient method to generate animal models to perform loss-of-function studies (Whitworth et al. 2014).

The present review will provide a brief background on the development of the clustered regularly interspersed short palindromic repeats (CRISPR)-Cas9 nuclease methodologies to target a specific edit in a gene of interest. Establishment of pregnancy in viviparous mammals is a highly regulated biological process in which the conceptus expresses multiple factors necessary for the proper development and survival to term. The following describes how gene editing provided a better insight into the role of specific conceptus genes in porcine development and survival.

\section{CRISPR-Cas9 gene editing}

Genome engineering in animals has been accelerated by utilization of CRISPR-Cas9 nuclease technologies (Pennisi 2013, Seruggia \& Montoliu 2014). The CRISPRCas9 nuclease gene-editing system allows a researcher to introduce targeted changes to the genome of a living cell. This technology was developed by utilizing the adaptive immunity defense intrinsic to some bacteria and archaea that results in the recognition and destruction of foreign DNA. After infection of the microbe by a mobile genetic element (e.g. phage, plasmid and transposon), the initial action of this adaptive immune response is to incorporate a portion of the foreign DNA into its CRISPR array. The natural CRISPR systems also include CRISPR-associated (Cas) genes that provide for various enzymatic activities. In one of those systems, all of the endonuclease activities have evolved to be harboured in a natural fusion gene, specifically the endonuclease Cas9, which cleaves the foreign DNA. Through an interaction with specific RNAs that provide sequence specificity by RNA/DNA base pairing, Cas 9 nuclease can be targeted to induce double-strand breaks (DSB) at specific locations in the genome. In nature, the result of DSB is destruction of the invading genetic element. In the laboratory, the result of DSB can be an intentional modification of a target gene. Drs Jennifer Doudna and Emmanuelle Charpentier recently received the Noble Prize in Chemistry for their discovery of CRISPR through their investigations of the potential of this bacterial immune system to be manipulated into a gene-editing technology (Jinek et al. 2012). They developed a simplified RNA component of the bacterial CRIPSR-Cas9 system, called guide RNA (gRNA). In the CRISPR-Cas9 gene-editing system, the targeted loci are cleaved by Cas9 resulting in a DSB that is followed by DNA repair via non-homologous end joining (NHEJ) or homologous directed repair (HDR). In the absence of a donor DNA template that would be used for HDR, the error-prone repair system NHEJ is used, resulting in bp deletions or insertions (Reis et al. 2014). Different software programs have been created to design and optimize CRISPR gRNA to a region of interest. The only requirement for this system is that the target DNA must be followed by a system-specific protospacer adjacent motif (PAM). For the commonly used CRISPR-Cas9 system from $S$. pyogenes, the PAM sequence is $5^{\prime}$-NGG3' (Sorek et al. 2013). To create gene-edited embryos and animals, the CRISPR-Cas9 system is commonly used in two ways: (1) direct zygote injection of either CRISPR gRNA (Ryu et al. 2018) or a Cas9/gRNA ribonucleotide/ protein complex or (2) somatic cell transfection of a plasmid system that expresses CRISPR gRNA and Cas9 protein complex, followed by nuclear transfer cloning techniques (Sorek et al. 2013). These two techniques have been successfully used in multiple species. A few examples include using CRISPR-Cas9 to create diseaseresistant animals that could be used in the swine industry. In pigs, the CRISPR-Cas9 system was used to edit the $C D 163$ gene which resulted in the pigs being resistant to porcine reproductive and respiratory syndrome (PRRS) virus which would normally cause severe reproductive failure in sows (Whitworth et al. 2016, Prather et al. 2017). In addition, ANPEP was knocked out resulting in pigs that are resistant to transmissible gastroenteritis virus (Whitworth et al. 2019), and more recently ANTXR1 was knocked out making pigs resistant to Senecavirus virus A (Chen and Prather unpublished data). The CRISPRCas9 system can be utilized on multiple mammalian species, providing an efficient way to generate animal models that can be used to understand gene function. The utilization of CRISPR-Cas9 gene-editing in porcine conceptuses provides a direct approach to investigate the specific role of conceptus factors in the development and establishment of pregnancy in the pig.

\section{Porcine conceptus development}

During early pregnancy, porcine conceptuses have an extended peri-implantation period following 
blastocyst hatching where there is continued growth of the spherical conceptuses to expand from 8 to $9 \mathrm{~mm}$ in diameter from days 8 to 12 of gestation (Fig. 1A). Porcine conceptuses transition to a tubular and thin filamentous form (Fig. 1B and C) by rapidly elongating to $>150 \mathrm{~mm}$ in length in 1-2 h (Geisert et al. 1982, Ross et al. 2009). Rapid conceptus elongation involves the development of outer trophectoderm and differentiation of the extra-embryonic mesoderm and endoderm that together drive cellular movement and morphology to a filamentous type conceptus (Geisert et al. 2015). Trophoblast elongation is essential as it initially establishes the uterine surface area that each individual fetus will occupy throughout gestation. The trophoblast continues to grow and expand between days 12 and 18 reaching lengths of $800-1000 \mathrm{~mm}$ and invaginating into the highly convoluted uterine epithelium. With trophoblast attachment, there is also differentiation of the embryo and expansion of the allantois (day 15) to form the placental vascular network. The majority of the expansion of the newly formed diffuse, epitheliochorial placenta (Fig. 1D) occurs by day 30 of gestation.

During peri-implantation development, porcine conceptuses synthesize and secrete multiple factors to stimulate the maternal endometrium to establish pregnancy and support placental and embryo growth and development. Conceptus production of interleukin 1 beta 2 (IL1B2), estrogens (E2), prostaglandins (PG) and interferons (IFN) have been intensively studied and proposed as major factors critical for conceptus

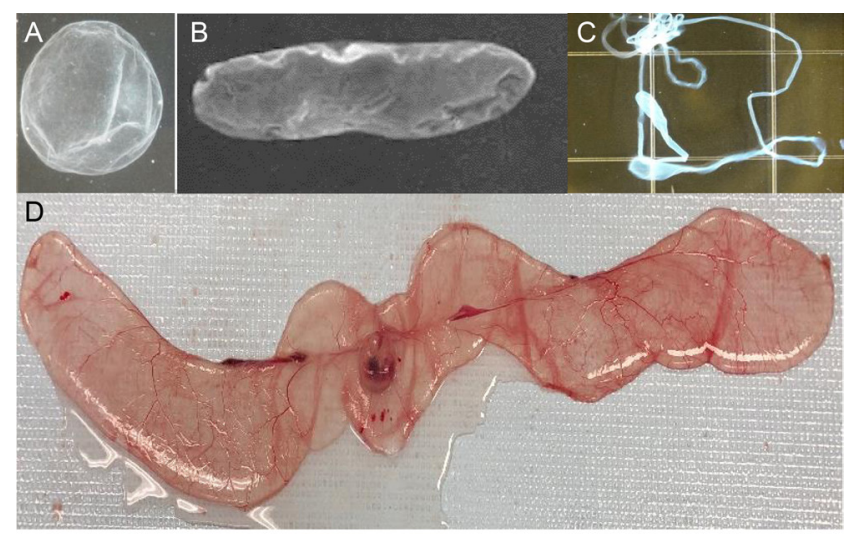

E

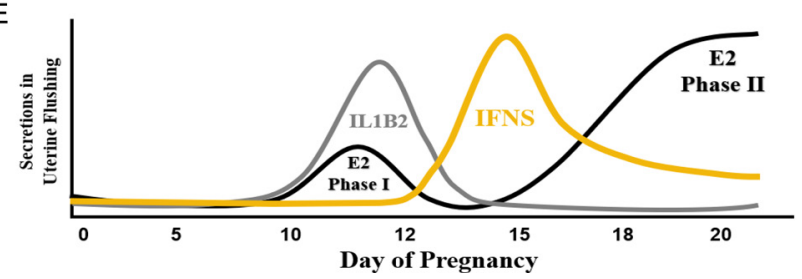

Figure 1 Conceptus and placental development in the pig. (A) Spherical (day 11), (B) tubular (day 12), (C) filamentous (day 12) and (D) day 30 placenta. (E) Relative changes of conceptus IL1B2, E2 and IFNs in uterine flushings during peri-implantation development and uterine attachment. development and survival (Fig. 2). Conceptus IL1B2 expression occurs at the time of rapid conceptus trophoblast elongation and has a spatiotemporal relation to conceptus E2 and PG synthesis (Geisert et al. 2015). Immediately following rapid trophoblast elongation and the initiation of attachment to the uterine surface epithelium, the porcine conceptuses express IFNs. Conceptus production of IL1B2, E2, PGs and IFNs have long been proposed to play essential roles in maternal recognition of pregnancy (maintenance of $\mathrm{CL}$ function beyond the length of a normal estrous cycle), stimulating endometrial secretions for growth and development, and maternal immune regulation (Geisert et al. 2015). The noninvasive placentation of the pig makes it possible to flush the uterine horns and collect conceptus and uterine secretions during the period of peri-implantation and attachment to the endometrial surface. CRISPR-Cas9 gene-editing provides a method to knockout specific conceptus gene(s). This enables direct evaluation of the role(s) of targeted conceptus factors in the establishment and maintenance of pregnancy in the pig. Establishing the fundamental roles of conceptus- and uterine-secreted factors are an essential step in developing strategies to increase placental and fetal growth and to improve the overall health and survivability of piglets before and after birth.

\section{Conceptus IL1B2 and trophoblast elongation}

Early transcriptome analysis identified ILIB2 as one of the most abundantly expressed genes during the period of rapid conceptus elongation in the pig (Tuo et al. 1996, Ross et al. 2003). IL1B1 is a proinflammatory cytokine which has been proposed to play a role in the inflammatory response associated with a variety of cellular activities such as cell proliferation, apoptosis and expression of cell adhesion molecules (Dinarello 2009). The pig conceptus is unique in that it expresses an embryo-specific IL1B isoform, IL1B2, which likely resulted from gene duplication (Mathew et al. 2015). Expression of IL1B2 mRNA increases sharply during conceptus elongation and has a dramatic decline with mRNA expression barely detectable after the conceptuses have elongated by day 13 of pregnancy (Ross et al. 2003). IL1B2 acts through its specific receptor (IL1R1) and initiates a cascade of signaling pathways through activation of nuclear factor kappa-B (NFKB) (Mathew et al. 2015), which has a biological role in sensing and adapting to alterations in the microenvironment of the immune system at the level of tissues and epithelia. IL1B induces the expression of phospholipase A2 (Kol et al. 2002), which is proposed to regulate the release of arachidonic acid from the phospholipid bilayer, allowing an increase in membrane fluidity, a necessary property for rapid remodeling of the trophectoderm during elongation (Ross et al. 2003). 


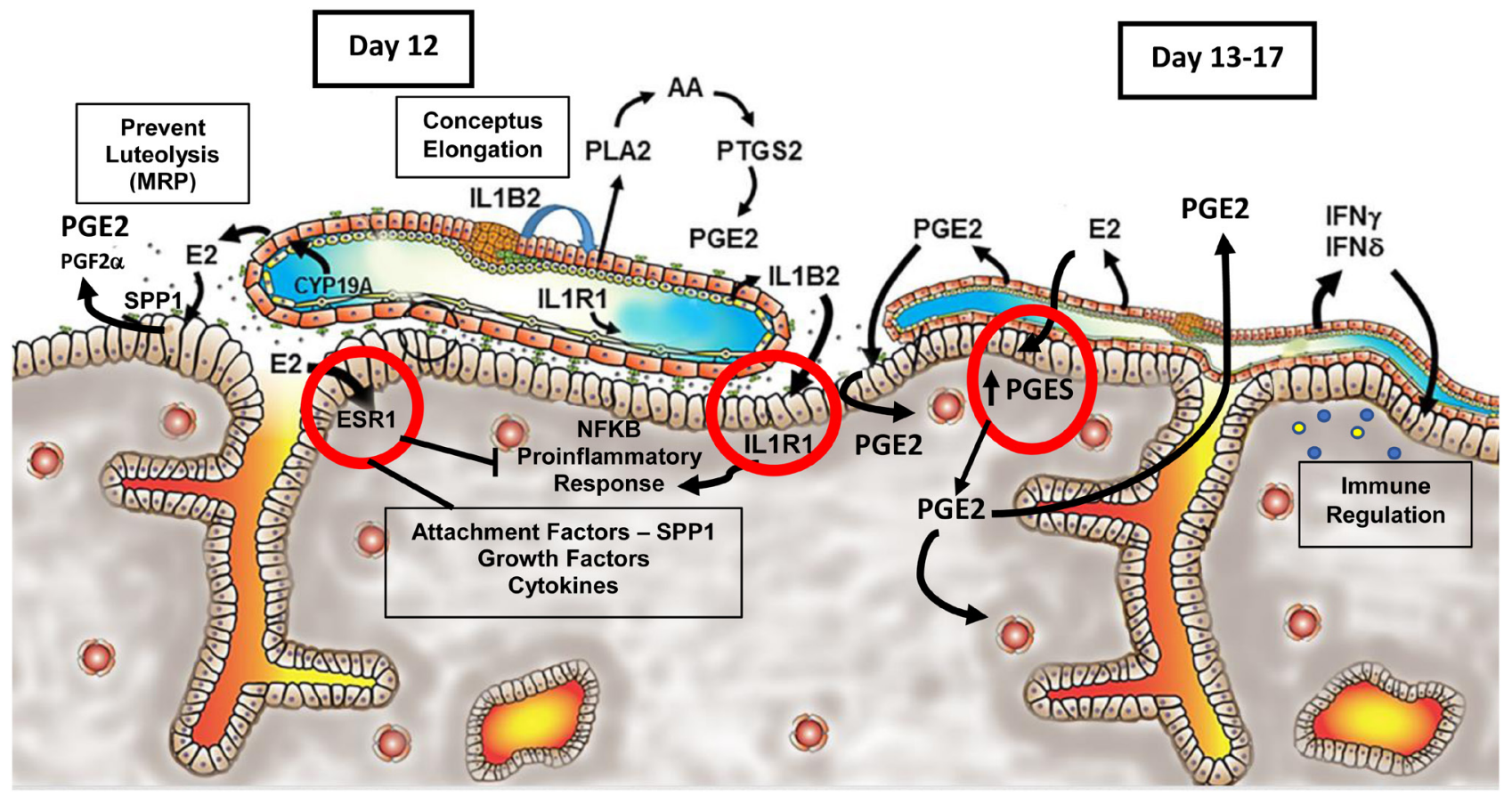

Figure 2 Schematic representation of signaling pathways between the endometrium and conceptus that regulate pig conceptus elongation and attachment during the establishment of pregnancy from days 12 to 17 of gestation. Expression of IL1B2 by the tubular conceptuses activates a cascade of biological processes needed to stimulate cellular movement and remodeling of the trophectoderm and endoderm during rapid elongation of the pig conceptus on day 12 of pregnancy. The spatiotemporal increase in conceptus CYP19A expression enhances synthesis and secretion of estrogen, which binds to endometrial ESR1 in the uterine epithelium to stimulate trophoblast attachment to the uterine luminal surface epithelium. Conceptus estrogen enhances the production of attachment factors (SPP1), growth factors and cytokines from the endometrium to stimulate conceptus growth and development. Conceptus estrogen stimulates the movement of prostaglandins into the uterine lumen. Increased endometrial and conceptus PGE2 production assists in the movement of prostaglandins into the uterine lumen, preventing PGF2a induction of luteolysis (CL regression) to maintain pregnancy. Conceptus IL1B2 secretion binds to its receptor (IL1R1) to activate NFKB to induce endometrial genes involved in stimulating proliferation, proinflammatory responses, and possibly lymphocyte trafficking into the endometrium. Estrogen may play a role in tempering the NFKB stimulation of endometrial inflammation by IL1B2. Immediately following conceptus elongation on day 13, conceptuses express and secrete IFND and IFNG which activates many IFN-induced genes which may help modulate the endometrial proinflammatory response and lymphocyte differentiation and activation within the uterine stroma and epithelium to prevent immunological rejection of the developing conceptuses. CYP19A, aromatase; E2, estrogen; ESR1, estrogen receptor 1 alpha; IL1B2, interleukin-1B2, IL1R1, interleukin 1 receptor 1; IFND, interferon delta; IFNG, interferon gamma; MRP, maternal recognition of pregnancy; NFKB, nuclear factor kappa-B; PLA2, phospholipase A2; PGF2a, prostaglandin F2 alpha; PGE2, prostaglandin E2; PTGS2, prostaglandinendoperoxide synthase 2; SPP1, secreted phosphoprotein 1.

Whyte et al. (2018) successfully created a loss-offunction edit in porcine fetal fibroblasts by using a gRNA specifically designed for IL1B2. A line of biallelic edited IL1B2 ${ }^{-/}$porcine fetal fibroblast cells were used for somatic cell nuclear transfer, in vitro culture and transfer to surrogate pigs. The IL1B2 null embryos were able to develop to the blastocyst stage and hatch from their zona pellucida. Although capable of developing into large spherical (8 to $9 \mathrm{~mm}$ ) conceptuses, these conceptuses failed to elongate, developed an abnormal morphology and failed to secrete detectable IL1B2 into the uterine lumen. In contrast, WT (non-edited fibroblast clones) donor cells resulted in embryos that elongated and secreted IL1B2 into the uterine lumen. This study established that porcine conceptus IL1B2 production is one of the factors that is essential for cellular remodeling of the porcine trophoblast during rapid conceptus elongation and embryo survival.

\section{Conceptus estrogen and pregnancy establishment}

Historically, conceptus production of E2 had been the proposed and accepted signal for maternal recognition of pregnancy in the pig (Bazer et al. 1984). In addition, E2 has been suggested to assist with the migration of the embryos and equidistant spacing of blastocyst stage embryos (day 8 to 12) within the uterine horns prior to the time of conceptus rapid elongation and attachment to the endometrial surface (Pope et al. 1982). As the ovoid pig conceptus rapidly elongates (Fig. 1), trophectodermal expression of aromatase (CYP19A) substantially increases (Conley et al. 1994, Kayser et al. 2006, Yelich et al. 1997). The biphasic increase in conceptus E2 synthesis on days 11 and 15-30 of gestation was considered essential for inhibiting luteolysis and the incremental attachment of the trophectoderm to the uterine surface (Geisert et al. 2014). Conceptus 
aromatase expression allows the synthesis of substantial amounts of E2 that acts through estrogen receptor 1 (ESR1) in the uterus to signal pregnancy recognition, stimulate uterine secretions and presumably regulate trophoblast attachment and placental development (Conley et al. 1994, Johnson et al. 2009). Conceptus E2 stimulates a large number of endometrial genes for the transcription of growth factors, attachment and adhesion proteins, prostaglandin synthesis, receptor signaling, ion transport and transporters of glucose and amino acids (Geisert et al. 2015).

Meyer et al. (2019) created biallelic edits for disruption of expression of CYP19A1 in a line of porcine fetal fibroblasts which were then used for somatic cell nuclear transfer to create embryos to evaluate the importance of conceptus-derived estrogen synthesis in the development and establishment of pregnancy. RNA-seq data from WT peri-implantation conceptuses indicated that only CYP19A1 aromatase is expressed in the trophectoderm with no evidence of other possible aromatase forms. Although pig conceptuses express aromatase and produce E2 prior to elongation, CYP19A1 $1^{--}$(null) embryos are capable of developing to the blastocyst stage, hatching, migrating and spacing in the uterine horns, elongating, and forming fluid-filled placentae (Meyer et al. 2019). We hypothesized that the inability of CYP19A $1^{-/-}$conceptuses to produce E2 and signal maternal recognition of pregnancy would result in a failure of maternal recognition of pregnancy and luteolysis on day 15 of pregnancy. Unexpectedly, although CYP19A $1^{-/}$conceptuses did not synthesize $\mathrm{E} 2$, the ovaries from recipient gilts carrying CYP19A1 $1^{-1-}$ conceptuses maintained their $\mathrm{CL}$ and progesterone secretion beyond day 25 of pregnancy. Thus, luteolysis can be inhibited up to day 22 to 25 of gestation in the absence of conceptus-derived E2 synthesis, well beyond the period of maternal recognition of pregnancy in the pig. These data should not be interpreted to indicate that conceptus E2 is not involved with repressing luteolysis during pregnancy, but other conceptus factors can support CL function as well. Multiple studies have clearly established that systemic or intrauterine administration of E2 between days 11 to 15 of the estrous cycle stimulates an increase in endometrial PGE synthesis and movement of the PG into the uterine lumen in a manner similar to that observed in pregnancy, extending the $\mathrm{CL}$ function beyond 30 days (Frank et al. 1977, Ford et al. 1982, Saunders et al. 1983, King \& Rajamahendran 1988). Geisert et al. (1987) demonstrated that the two periods of conceptus E2 production (day 12 and 15-18) during establishment of pregnancy were necessary to maintain CL function beyond 30 days in E2-treated cyclic gilts. Thus, conceptus E2 production appears to be essential to maintain pregnancy after day 15 as CYP19A1 $1^{--}$conceptus recipients returned to estrus or aborted by day 25 to 32 of pregnancy (Meyer et al. 2019). Although attempts to rescue the $C L$ and maintain plasma progesterone concentrations in recipient gilts containing CYP19A $1^{-/-}$conceptuses beyond 30 days with exogenous E2 during the period of maternal recognition of pregnancy were successful, pregnancy still failed. However, pregnancy of $\mathrm{CYP}_{19 \mathrm{~A} 1^{-/-}}$ conceptuses could be rescued by co-transferring in vitro fertilized WT embryos. The ability of WT embryos to rescue the CYP19A1 ${ }^{-/-}$embryos may be due to the better development and capacity for E2 synthesis of WT embryos in utero since the concentration of estradiol$17 \beta$ in allantoic fluid of WT placentae was $3500 \mathrm{pg} / \mathrm{mL}$ compared to $50 \mathrm{pg} / \mathrm{mL}$ in the placentae of the rescued CYP19A1 $1^{-/}$embryos (Meyer, Pfeiffer, and Geisert, unpublished data).

Although preimplantation and placental development were not affected by the loss of estrogen synthesis in CYP19A $1^{-/}$porcine conceptuses, endometrial gene expression patterns on days 14 and 17 were markedly altered (Meyer etal. 2019). A large number of differentially expressed genes involved in proinflammatory pathways were upregulated in the endometrium of CYP19A $1^{-1-}$ conceptus recipient gilts. Many other differentially expressed genes encoded for solute carriers, cell vesicle transport and the extracellular matrix. Interestingly, several endometrial genes which are proposed to be estrogen regulated were not altered in recipients with $\mathrm{CYP} 19 \mathrm{~A} 1^{-/-}$conceptuses, suggesting that other conceptus factors can stimulate these pathways in the absence of conceptus estrogen.

The porcine aromatase knockout model provided clear evidence of the essential role of placental estrogen in maintenance of pregnancy and continued embryonic survival beyond 24 days of gestation. The absence of conceptus estrogen production, which altered early endometrial gene expression, may have downstream effects on uterine extracellular matrix and proinflammatory pathways leading to uterine immune responses and abortion. Many studies have documented the role of high concentrations of $\mathrm{E} 2$ in mediating immune responses during pregnancy (Trenti et al. 2018). The role of estrogens at the placental interface with the maternal uterine surface may be similar to how specific tumors utilize E2 to inhibit and protect the malignant cells from immunological recognition and rejection (Zang et al. 2002). If so, the absence of placental E2 at the maternal uterine placental interface would be detrimental to the regulation of proinflammatory responses and localized release of cytokines from immune cells trafficking below the endometrial luminal epithelial surface.

\section{Conceptus prostaglandins and pregnancy establishment}

The results of Meyer et al. (2019) provided evidence that the pig has alternative pathways which serve to protect the CL from luteolysis (maternal recognition) with and without conceptus estrogen production during the 
early implantation window. Conceptus prostaglandin synthesis has been proposed to be involved with early CL maintenance (Waclawik et al. 2009a) and regulation of endometrial function during pregnancy (Waclawik et al. 2017). Inhibition of prostaglandin synthesis causes conceptus loss during early pregnancy in the pig (Kraeling et al. 1985), implying that conceptus and endometrial prostaglandins play a pivotal role in early embryonic development and survival beyond $\mathrm{CL}$ maintenance. Since conceptus and possibly endometrial PGE2 can maintain progesterone production, PGE2 likely has a direct luteoprotective role during the establishment of pregnancy in the pig (Henderson et al. 1977, Ford \& Christenson 1991). Conceptus prostaglandin synthesis is dependent on the expression of prostaglandinendoperoxide synthase (PTCS) 1 and 2. While pig conceptus PTGS1 expression is low to undetectable until the time of placental attachment (day 14-18), conceptus PTGS2 is highly expressed concurrently with blastocyst development and the period of rapid trophoblastic elongation on day 12 (Waclawik \& Ziecik 2007).

Pfeiffer et al. (2020) successfully ablated the porcine PTCS2 gene and protein expression (Fig. 2) by using the CRISPR-Cas9 gene-editing system. Porcine blastocyst stage embryos and early day 12 conceptuses do not produce PTGS1 as it is not detected until after the initiation of uterine trophoblast attachment on day 13 (Wilson et al. 2002). Therefore, disrupting conceptus PTCS2 expression allowed for a greater understanding of the function of PTGS2 during the period of elongation, maternal recognition and placental development in the pig.

Blastocyst stage embryo expression of PTGS2 is detected across many species (Marshburn et al. 1990, Gurevich \& Shemesh 1994, Charpigny et al. 1997). In a few species, prostaglandins have been suggested to support blastocyst formation and hatching (Roy \& Seshagiri 2013). Despite the complete lack of PG synthesis by the porcine PTGS2-1- embryos during in vitro culture (Fig. 3A), the embryos developed to the blastocyst stage and were capable of hatching (Pfeiffer et al. 2020). In addition, despite the decrease in PG synthesis, conceptuses were not only capable of migrating, elongating and maintaining $C L$ function but also in establishing and maintaining pregnancy to day 35 of gestation (Fig. 3C). Similarly, PTGS2 null ovine conceptuses elongate normally (O'Neil et al. 2020).

Although PTGS2-'- conceptus PG production was significantly decreased on days 14 and 17 of pregnancy in the pig, the content of PGs in uterine luminal flushing was not affected, indicating the large contribution of the endometrium to PG production during early pregnancy. It is also possible that conceptus uptake of endometrial PGs could ensure that a substrate is available for PGE synthesis. Therefore, conceptus production of E2 could possibly compensate for the lack of PTGS2-derived prostaglandins as estrogens increase endometrial
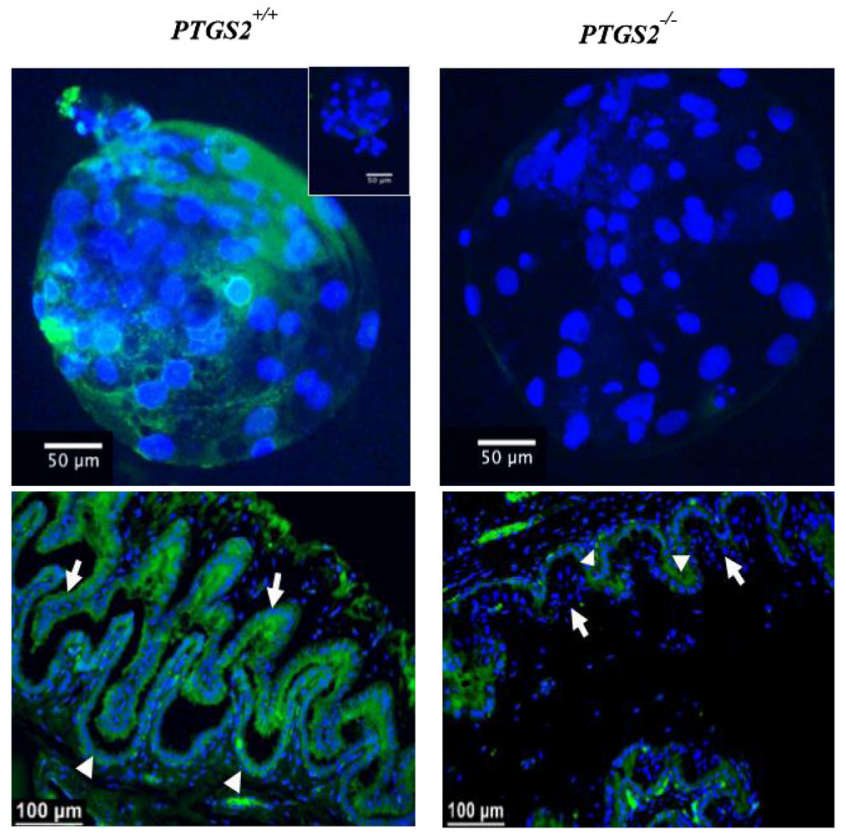

Figure 3 Immunolocalization of PTGS2 in PTGS2 ${ }^{+/+}$and PTGS2-'blastocysts (A and B) and day 35 placental-uterine sections ( $\mathrm{C}$ and D). Endometrial LE (arrow heads) and placental chorion (arrows). Inset: negative control PTGS2 ${ }^{+/+}$blastocyst (Pfeiffer et al. 2020).

PTGS2 expression and production of PGE2 (Waclawik et al. 2009ab). The development of a double gene edit (CYP19A1-'- and PTCS2-'-) is necessary to directly address the question of whether conceptus E2 and PGs (PGE) work together as maternal recognition of pregnancy signals in the pig.

\section{Conceptus IFNG and pregnancy establishment}

During and following rapid conceptus elongation in the pig on day 12 of pregnancy, there is an immediate increase in expression and secretion of both a type I (IFND) and type II (IFNG) interferon (Bazer et al. 2009, Bazer \& Johnson 2014). Interferons, noted for their antiviral activity, peak in the uterine flushings of pregnant pigs on days 14 and 15 but remain detectable until day 20 of pregnancy (Mirando et al. 1990). Although porcine conceptuses are unique in that they express both IFND and IFNG, INFG is the predominant IFN expressed by the trophoblast during early attachment to the uterine surface (Cencic \& La Bonnardière 2002, Joyce et al. 2007). Type I IFND and type II IFNG bind to two different cell surface receptors, both of which belong to the class II cytokine receptor subfamily. IFND binds a cell surface heterodimeric receptor comprising IFNAR1 and IFNAR2, while IFNG binds to a heterodimer of IFNGR1 and IFNGR2 (Platanias 2005). These IFN receptors (IFNGR1 and IFNGR2 mRNAs) are expressed in the endometrium and conceptuses during early pregnancy and chorioallantoic tissues during mid to late pregnancy (Bazer \& Johnson 2014). The presence of trophoblast 
IFN receptors indicate conceptus IFND, and IFNG may have both paracrine and autocrine effects in utero.

Porcine conceptus IFNG expression has been proposed to play a role in conceptus attachment to the endometrium through its involvement in regulating integrins and heparin sulfate proteoglycans (Farrar \& Schreiber 1993). It has been suggested that both IFNG and IFND can contribute to a remodeling of the endometrial epithelium, affecting its polarity and receptivity to the trophoblast, thus favouring trophoblast attachment (D'Andrea et al. 1994). IFNG increases the expression of many endometrial genes, including class I and II major histocompatibility complexes, STAT1, and IRF1 which are all involved in immune regulation (Joyce et al. 2007, 2008, Yoo et al. 2019). Yoo et al. (2020) indicated that IFNG regulates a large number of endometrial genes that are involved with maternal immune cells and immune tolerance during conceptus attachment to the luminal epithelium and placental development. Although studies have established the period of pig conceptus synthesis of IFNG and IFND during pregnancy and the effects of IFNG on endometrial gene expression in vitro, the role of IFNG and IFND in the establishment and maintenance of pregnancy is unknown.

Whereas conceptus IFNG is encoded by a single gene, type I IFND consists of a family of possibly 11 different genes (Isom et al. 2013). Porcine conceptus expression of IFND1 and IFND2 is detectable when evaluated by RT-PCR on days 14,17 and 34 of pregnancy with low to no detection of the other isoforms during the preimplantation period (Johns, Wells \& Geisert unpublished results). As expected, conceptus IFNG was only detected during conceptus preimplantation development. Since IFNG (major conceptus IFN released) is encoded by only a single gene and binds to a different receptor from IFND during the preimplantation period, we utilized CRISPRCas9 gene editing to specifically target IFNG expression in our line of porcine fetal fibroblasts which then were utilized for somatic nuclear transfer and production of blastocyst-stage embryos for embryo transfer. As expected, IFNG ${ }^{-/-}$conceptus development, uterine migration and rapid elongation were unaltered since IFNG expression occurs after conceptus elongation on day 14 of pregnancy (Johns, Wells, Spencer \& Geisert, unpublished data). The IFNG protein was not detected in the trophoblast of IFNG ${ }^{-/}$conceptuses (Fig. 4) and the content of IFNG was 10-fold lower in the uterine flush of recipients containing IFNG ${ }^{-/}$conceptuses compared to $\mathrm{IFNG}^{+/+}$recipients. The absence of conceptus IFNG appears to cause a strong inflammatory response as indicated by conceptus fragmentation, endometrial hyperemia, edema and inflammation (Johns, Wells, Spencer \& Geisert, unpublished data). The proinflammatory response by the endometrium and the cause of conceptus loss need to be evaluated. Certainly, the IFNG ${ }^{-1}$ - conceptuses provide a model to investigate the essential role of IFNG in regulating maternal

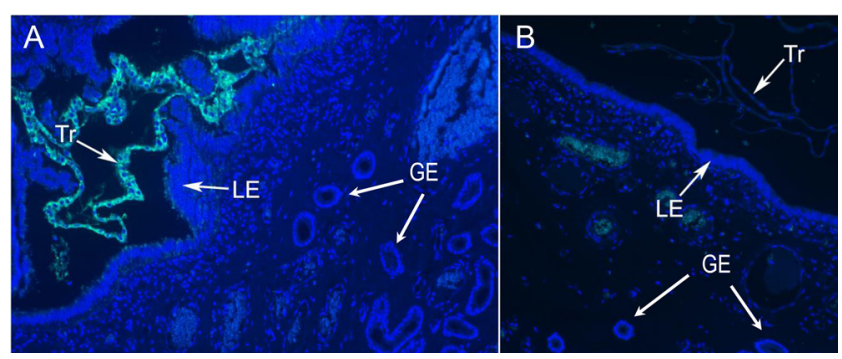

Figure 4 Immunofluorescent staining for IFNG at sites of implantation on day 15 of pregnancy. Positive staining (green) in the trophectoderm (Tr) of (A) WT conceptuses but no signal was detectable in the (B) trophectoderm of IFNG ${ }^{-/-}$conceptuses. LE, luminal epithelium; GE,glandular epithelium (10x). Picture provided by Dr Heewon Seo (Texas A\&M University).

responses during the period of placental attachment and development in the pig.

IFNG plays a role in the establishment and maintenance of pregnancy at the maternal-fetal interface in humans and mice. In mice, IFNG production is detectable at the implantation sites, with the highest levels on day 10 but, unlike pig conceptuses, the main source of IFNG is uterine natural killer (uNK) cells (Ashkar \& Croy 1999). The major function of IFNG during murine pregnancy is to initiate uterine vascular modification and change decidual cellular integrity to facilitate the pregnancy-induced remodeling of decidual arteries (Ashkar et al. 2000). During early pregnancy in humans, IFNG is produced by uNKs in decidua and trophoblast, but IFNG does not increase significantly in the endometrium during the period of embryo receptivity (Murphy et al. 2009). IFNG regulates trophoblastic invasion, the recruitment of peripheral NK cells into the decidua and aberrant decidual matrix metalloproteases ( $\mathrm{Fu}$ et al. 2013, Lockwood et al. 2014). Although some roles of IFNG at the maternal-fetal interface have been elucidated in humans and mice, the detailed functions of IFNG during pregnancy are not fully understood in any species, perhaps because IFNG is not produced in large amounts during the pregnancies of other species, and IFNG null mice are healthy and fertile, even though they have compromised macrophage function and are highly susceptible to infection (Dalton et al. 1993). The role of IFNs in conceptus uterine survival may be related to the type of implantation. The noninvasive implantation and diffuse, epitheliochorial type of placentation in the pig contrasts the invasive, uterine decidual response to placentation exhibited in rodents and humans. Conceptus expression of IFNG in the pig and IFNT in cattle and sheep (Bazer et al. 2009) may serve an essential role in attachment of the trophoblast to the uterine surface and maternal immune regulation during the early stages of placental formation. Although the invasive horse conceptus does not have a major expression of an IFN, the endometrium constitutively 
expresses IFN-epsilon (IFNE) which is upregulated during the luteal phase of the estrous cycle (Fischer et al. 2018). Lack of conceptus IFN expression in the horse may be related to the presence of a protective capsule which surrounds the conceptus until day 20 of gestation (Allen 2001) and delays direct attachment of the placenta to the uterine surface. The constitutive endometrial IFN-epsilon expression may serve to regulate the maternal innate immune system until loss of the capsule and direct attachment occurs.

\section{Conclusion}

The development of CRISPR-Cas9 gene-editing has provided a powerful tool to directly investigate the role of specific conceptus factors in the establishment and maintenance of pregnancy. This technology has allowed us to establish that IL1B2 is involved with rapid conceptus elongation in the pig and leads to abnormal development if knocked out. We also generated data indicating that conceptus estrogen synthesis is not essential for maternal recognition of pregnancy but is necessary for maintenance of pregnancy after day 25 of gestation. Additionally, conceptus expression of PTCS2 and production of PGs are not essential for the establishment and maintenance of pregnancy. Although the conceptus CYP19A1 and PTGS2 knockout model could suggest that neither is involved in maternal recognition of pregnancy in the pig, historical studies would support a conclusion that both can provide a signal to prevent luteolysis in the absence of the other. Recently, Kaczynski et al. (2021) indicated a synergistic endometrial transcriptome response to E2 and PGE2 that more closely replicated pregnancy than the response to either E2 or PGE2 alone. The role of both conceptus estrogen and prostaglandin E synthesis in maternal recognition of the pig can be addressed through creating a double knockout in the future. The loss of pregnancy (abortion) after placental formation in embryos with an aromatase null placenta provides a model to understand the role of estrogen not only in the pig but also in other species. Finally, we established that conceptus IFNG expression is essential for conceptus regulation of attachment and survival within the maternal uterus. Future analysis of the endometrial response to IFNG null conceptuses will provide clues to the conceptus regulation of maternal immune system during the establishment of pregnancy. CRISPR-Cas9 gene-editing has provided a method to investigate key factors across many biological pathways involved with reproduction. The ability to target specific genes in early conceptus and later placental development will help to define key pathways regulating placental growth and fetal health across a number of species including humans.

\section{Declaration of interest}

The authors declare that there is no conflict of interest that could be perceived as prejudicing the impartiality of this review.

\section{Funding}

This work was funded by Agriculture and Food Research Initiative Competitive Grant no. 2017-67015-26451 from the USDA National Institute of Food and Agriculture (R D G, R $S P$ and T E S). The funders had no role in study design, data collection and analysis, decision to publish, or preparation of the manuscript.

\section{Author contribution statement}

R D G was responsible for the original manuscript. A E M, C A $P$ and $D N$ J were responsible for conducting the investigations that provided the original research results that contributed to the review. K L, K D W, T E S and R S P provided supervision and crucial intellectual input into the design, writing and approval of this work.

\section{References}

Allen WR 2001 Fetomaternal interactions and influences during equine pregnancy. Reproduction 121 513-527. (https://doi.org/10.1530/ rep.0.1210513)

Amoroso EC 1952 Placentation. In Marshall's Physiology of Reproduction, 3rd ed., Vol. 2, pp. 127-311. Ed AS Parkes. London: Longmans.

Ashkar AA \& Croy BA 1999 Interferon-gamma contributes to the normalcy of murine pregnancy. Biology of Reproduction 61 493-502. (https://doi. org/10.1095/biolreprod61.2.493)

Ashkar AA, Di Santo JP \& Croy BA 2000 Interferon gamma contributes to initiation of uterine vascular modification, decidual integrity, and uterine natural killer cell maturation during normal murine pregnancy. Journal of Experimental Medicine 192 259-270. (https://doi.org/10.1084/ jem.192.2.259)

Bazer FW \& Johnson GA 2014 Pig blastocyst-uterine interactions. Differentiation: Research in Biological Diversity 87 52-65. (https://doi. org/10.1016/j.diff.2013.11.005)

Bazer FW, Marengo SR, Geisert RD \& Thatcher WW 1984 Exocrine versus endocrine secretion of prostaglandin $\mathrm{F}$ in the control of pregnancy in swine. Animal Reproductive Science 7 115-132. (https://doi. org/10.1016/0378-4320(84)90031-9)

Bazer FW, Spencer TE \& Johnson GA 2009 Interferons and uterine receptivity. Seminars in Reproductive Medicine 27 90-102. (https://doi. org/10.1055/s-0028-1108013)

Cencic A \& La Bonnardière C 2002 Trophoblastic interferon-gamma: current knowledge and possible role(s) in early pig pregnancy. Veterinary Research 33 139-157. (https://doi.org/10.1051/vetres:2002003)

Charpigny G, Reinaud P, Tamby JP, Creminon C \& Guillomot M 1997 Cyclooxygenase-2 unlike cyclooxygenase-1 is highly expressed in ovine embryos during the implantation period. Biology of Reproduction $\mathbf{5 7}$ 1032-1040. (https://doi.org/10.1095/biolreprod57.5.1032)

Conley AJ, Christenson LK, Ford SP \& Christenson RK 1994 Immunocytochemical localization of cytochromes P450 17 alphahydroxylase and aromatase in embryonic cell layers of elongating porcine blastocysts. Endocrinology 135 2248-2225. (https://doi. org/10.1210/endo.135.5.7956948)

Dalton DK, Pitts-Meek S, Keshav S, Figari IS, Bradley A \& Stewart TA 1993 Multiple defects of immune cell function in mice with disrupted interferon-gamma genes. Science 259 1739-1742. (https://doi. org/10.1126/science.8456300) 
D'Andrea S, Chousterman S, Flechon JE \& La Bonnardière C 1994 Paracrine activities of porcine trophoblastic interferons. Journal of Reproduction and Fertility 102 185-194. (https://doi.org/10.1530/jrf.0.1020185)

Dinarello CA 2009 Immunological and inflammatory functions of the interleukin-1 family. Annual Review of Immunology 27 519-550. (https://doi.org/10.1146/annurev.immunol.021908.132612)

Farrar MA \& Schreiber RD 1993 The molecular cell biology of interferongamma and its receptor. Annual Review of Immunology 11 571-611. (https://doi.org/10.1146/annurev.iy.11.040193.003035)

Fischer CD, Wachoski-Dark GL, Grant DM, Bramer SA \& Klein C 2018 Interferon epsilon is constitutively expressed in equine endometrium and up-regulated during the luteal phase. Animal Reproduction Science 195 38-43. (https://doi.org/10.1016/j.anireprosci.2018.05.003)

Ford SP \& Christenson LK 1991 Direct effects of oestradiol-17 beta and prostaglandin E-2 in protecting pig corpora lutea from a luteolytic dose of prostaglandin F-2 alpha. Journal of Reproduction and Fertility 93 203-209. (https://doi.org/10.1530/jrf.0.0930203)

Ford SP, Magness RR, Farley DB \& Van Orden DE 1982 Local and systemic effects of intrauterine estradiol-17 beta on luteal function of nonpregnant sows. Journal of Animal Science 55 657-64. (https://doi.org/10.2527/ jas1982.553657x)

Frank M, Bazer FW, Thatcher WW \& Wilcox CJ 1977 A study of prostaglandin F2alpha as the luteolysin in swine: III effects of estradiol valerate on prostaglandin F, progestins, estrone and estradiol concentrations in the utero-ovarian vein of nonpregnant gilts. Prostaglandins 14 1183-1196. (https://doi.org/10.1016/0090-6980(77)90295-7)

Fu B, Li X, Sun R, Tong X, Ling B, Tian Z \& Wei H 2013 Natural killer cells promote immune tolerance by regulating inflammatory $\mathrm{TH} 17$ cells at the human maternal-fetal interface. PNAS 110 E231-E240. (https://doi. org/10.1073/pnas.1206322110)

Geisert RD \& Bazer FW 2015 Regulation of implantation and establishment of pregnancy in mammals. In Tribute to 45 Year Anniversary of Roger V. Short's 'Maternal Recognition of Pregnancy'. Eds RD Geisert \& FW Bazer. Advances in Anatomy, Embryology and Cell Biology. Springer.

Geisert RD, Brookbank JW, Roberts RM \& Bazer FW 1982 Establishment of pregnancy in the pig: II. Cellular remodeling of the porcine blastocyst during elongation on day 12 of pregnancy. Biology of Reproduction 27 941-955. (https://doi.org/10.1095/biolreprod27.4.941)

Geisert RD, Biggers BG, Wettemann RP \& Zavy MT 1987 Length of pseudopregnancy and pattern of uterine protein release as influenced by time and duration of oestrogen administration in the pig. Journal of Reproduction and Fertility 79 163-172. (https://doi.org/10.1530/ jrf.0.0790163)

Geisert RD, Lucy MC, Whyte JJ, Ross JW \& Mathew DJ 2014 Cytokines from the pig conceptus: roles in conceptus development in pigs. Journal of Animal Science and Biotechnology 5 51. (https://doi.org/10.1186/20491891-5-51)

Geisert RD, Johnson GA \& Burghardt RC 2015 Implantation and establishment of pregnancy in the pig. In Regulation of Implantation and Establishment of Pregnancy in Mammals: Tribute to 45 Year Anniversary of Roger V. Short's 'Maternal Recognition of Pregnancy', pp. 137-164. Eds RD Geisert \& FW Bazer. Advances in Anatomy, Embryology, and Cell Biology. Springer. (https://doi.org/10.1007/978-3-319-15856-3_8)

Gurevich M \& Shemesh M 1994 Induction of cyclooxygenase and prostaglandin E2 production by the bovine pre-embryo. Reproduction, Fertility, and Development 6 687-691. (https://doi.org/10.1071/ rd9940687)

Henderson KM, Scaramuzzi RJ \& Baird DT 1977 Simultaneous infusion of prostaglandin E2 antagonizes the luteolytic action of prostaglandin F2alpha in vivo. Journal of Endocrinology 72 379-383. (https://doi. org/10.1677/joe.0.0720379)

Isom SC, Stevens JR, Li R, Spollen WG, Cox L, Spate LD, Murphy CN \& Prather RS 2013 Transcriptional profiling by RNA-Seq of peri-attachment porcine embryos generated by a variety of assisted reproductive technologies. Physiological Genomics 45 577-589. (https://doi. org/10.1152/physiolgenomics.00094.2012)

Jinek M, Chylinski K, Fonfara I, Hauer M, Doudna JA \& Charpentier E 2012 A programmable dual-RNA-guided DNA endonuclease in adaptive bacterial immunity. Science 337 816-821. (https://doi.org/10.1126/ science.1225829)

Johnson GA, Bazer FW, Burghardt RC, Spencer TE, Wu G \& Bayless KJ 2009 Conceptus-uterus interactions in pigs: endometrial gene expression in response to estrogens and interferons from conceptuses. Society of Reproduction and Fertility Supplement 66 321-332.

Joyce MM, Burghardt RC, Geisert RD, Burghardt JR, Hooper RN, Ross JW, Ashworth MD \& Johnson GA 2007 Pig conceptuses secrete estrogen and interferons to differentially regulate uterine STAT1 in a temporal and cell type-specific manner. Endocrinology 148 4420-4431. (https://doi. org/10.1210/en.2007-0505)

Joyce MM, Burghardt JR, Burghardt RC, Hooper RN, Bazer FW \& Johnson GA 2008 Uterine MHC class I molecules and beta 2-microglobulin are regulated by progesterone and conceptus interferons during pig pregnancy. Journal of Immunology 181 2494-2505. (https:// doi.org/10.4049/jimmunol.181.4.2494)

Kaczynski P, Bauersachs S, Goryszewska E, Baryla M \& Waclawik A 2021 Synergistic action of estradiol and PGE2 on endometrial transcriptome in vivo resembles pregnancy effects better than estradiol alone. Biology of Reproduction ioaa230 In press. (https://doi.org/10.1093/biolre/ioaa230)

Kayser JP, Kim JG, Cerny RL \& Vallet JL 2006 Global characterization of porcine intrauterine proteins during early pregnancy. Reproduction 131 379-388. (https://doi.org/10.1530/rep.1.00882)

King GJ \& Rajamahendran R 1988 Comparison of plasma progesterone profiles in cyclic, pregnant, pseudopregnant and hysterectomized pigs between 8 and 27 days after oestrus. Journal of Endocrinology 119111 116. (https://doi.org/10.1677/joe.0.1190111)

Kol S, Kehat I \& Adashi EY 2002 Ovarian interleukin-1-induced gene expression: privileged genes threshold theory. Medical Hypotheses $\mathbf{5 8}$ 6-8. (https://doi.org/10.1054/mehy.2001.1389)

Kraeling RR, Rampacek GB \& Fiorello NA 1985 Inhibition of pregnancy with indomethacin in mature gilts and prepuberal gilts induced to ovulate. Biology of Reproduction 32 105-110. (https://doi.org/10.1095/ biolreprod32.1.105)

Lockwood CJ, Basar M, Kayisli UA, Guzeloglu-Kayisli O, Murk W, Wang J, De Paz N, Shapiro JP, Masch RJ, Semerci N et al. 2014 Interferongamma protects first-trimester decidual cells against aberrant matrix metalloproteinases 1, 3, and 9 expression in preeclampsia. American Journal of Pathology 184 2549-2559. (https://doi.org/10.1016/j. ajpath.2014.05.025)

Marshburn PB, Shabanowitz RB \& Clark MR 1990 Immunohistochemicallocalization of prostaglandin $\mathrm{H}$ synthase in the embryo and uterus of the mouse from ovulation through implantation. Molecular Reproduction and Development 25 309-316. (https://doi. org/10.1002/mrd.1080250402)

Mathew DJ, Newsom EM, Guyton JM, Tuggle CK, Geisert RD \& Lucy MC 2015 Activation of the transcription factor nuclear factor-kappa B in uterine luminal epithelial cells by interleukin-1 beta 2: a novel interleukin-1 expressed by the elongating pig conceptus. Biology of Reproduction 92 107. (https://doi.org/10.1095/biolreprod.114.126128)

Meyer AE, Pfeiffer CA, Brooks KE, Spate LD, Benne JA, Cecil R, Samuel MS, Murphy CN, Behura S, McLean MK et al. 2019 New perspective on conceptus estrogens in maternal recognition and pregnancy establishment in the pigt. Biology of Reproduction 101 148-161. (https://doi.org/10.1093/biolre/ioz058)

Mirando MA, Harney JP, Beers S, Pontzer CH, Torres BA, Johnson HM \& Bazer FW 1990 Onset of secretion of proteins with antiviral activity by pig conceptuses. Journal of Reproduction and Fertility 88 197-203. (https://doi.org/10.1530/jrf.0.0880197)

Murphy SP, Tayade C, Ashkar AA, Hatta K, Zhang J \& Croy BA 2009 Interferon gamma in successful pregnancies. Biology of Reproduction 80 848-859. (https://doi.org/10.1095/biolreprod.108.073353)

O'Neil EV, Brooks K, Burns GW, Ortega MS, Denicol AC, Aguiar LH, Pedroza GH, Benne J \& Spencer TE 2020 Prostaglandin-endoperoxide synthase 2 is not required for preimplantation ovine conceptus development in sheep. Molecular Reproduction and Development $\mathbf{8 7}$ 142-151. (https://doi.org/10.1002/mrd.23300)

Pennisi E 2013 The CRISPR craze. Science 341 833-836. (https://doi. org/10.1126/science.341.6148.833)

Perry JS 1981 The mammalian fetal membranes. Journal of Reproduction and Fertility 62 321-335. (https://doi.org/10.1530/jrf.0.0620321)

Pfeiffer CA, Meyer AE, Brooks KE, Chen PR, Milano-Foster J, Spate LD, Benne JA, Cecil RF, Samuel MS, Ciernia LA et al. 2020 Ablation of conceptus PTGS2 expression does not alter early conceptus development and establishment of pregnancy in the pig. Biology of Reproduction 102 475-488. (https://doi.org/10.1093/biolre/ioz192) 
Platanias LC 2005 Mechanisms of type-I- and type-II-interferon-mediated signalling. Nature Reviews: Immunology 5 375-386. (https://doi. org/10.1038/nri1604)

Pope WF, Maurer RR \& Stormshak F 1982 Intrauterine migration of the porcine embryo: influence of estradiol-17 beta and histamine. Biology of Reproduction 27 575-579. (https://doi.org/10.1095/biolreprod27.3.575)

Prather RS, Wells KD, Whitworth KM, Kerrigan MA, Samuel MS, Mileham A, Popescu LN \& Rowland RRR 2017 Knockout of maternal CD163 protects fetuses from infection with porcine reproductive and respiratory syndrome virus (PRRSV). Scientific Reports 7 13371. (https:// doi.org/10.1038/s41598-017-13794-2)

Reis A, Hornblower B, Robb B \& Tzertzinis G 2014 CRISPR/Cas9 and targeted genome editing: a new era in molecular biology. New England Biolabs Expressions 1 1-5.

Roberts RM, Green JA \& Schulz LC 2016 The evolution of the placenta. Reproduction 152 R179-R189. (https://doi.org/10.1530/REP-16-0325)

Ross JW, Malayer JR, Ritchey JW \& Geisert RD 2003 Characterization of the interleukin-1 $\beta$ system during porcine trophoblastic elongation and early placental attachment. Biology of Reproduction 69 1251-1259. (https://doi.org/10.1095/biolreprod.103.015842)

Ross JW, Ashworth MD, Stein DR, Couture OP, Tuggle CK \& Geisert RD 2009 Identification of differential gene expression during porcine conceptus rapid trophoblastic elongation and attachment to uterine luminal epithelium. Physiological Genomics 36 140-148. (https://doi. org/10.1152/physiolgenomics.00022.2008)

Roy S \& Seshagiri PB 2013 Expression and function of cyclooxygenase-2 is necessary for hamster blastocyst hatching. Molecular Human Reproduction 19 838-851. (https://doi.org/10.1093/molehr/gat063)

Ryu J, Prather RS \& Lee K 2018 Use of gene-editing technology to introduce targeted modifications in pigs. Journal of Animal Science and Biotechnology 9 5. (https://doi.org/10.1186/s40104-017-0228-7)

Saunders MJ, Edgerton LA, Kagan JM, Stahly TS \& Cromwell GL 1983 Comparison of intrauterine and subcutaneous sites of estrogen injection for luteal maintenance in swine. Journal of Animal Science 57 146-149. (https://doi.org/10.2527/jas1983.571146x)

Seruggia D \& Montoliu L 2014 The new CRISPR-Cas system: RNA-guided genome engineering to efficiently produce any desired genetic alteration in animals. Transgenic Research 23 707-716. (https://doi.org/10.1007/ s11248-014-9823-y)

Sorek R, Lawrence CM \& Wiedenheft B 2013 CRISPR-mediated adaptive immune systems in bacteria and archaea. Annual Review of Biochemistry 82 237-266. (https://doi.org/10.1146/annurev-biochem-072911-172315)

Spencer TE \& Bazer FW 2004 Uterine and placental factors regulating conceptus growth in domestic animals. Journal of Animal Science $\mathbf{8 2}$ E4-13. (https://doi.org/10.2527/2004.8213_supplE4x)

Telugu BP \& Pence L 2021 Development of pre-implantation mammalian blastocyst in placentation in mammals: tribute to E.C. Amoroso's lifetime contributions to viviparity. Advances in Anatomy, Embryology and Cell Biology In press.

Trenti A, Tedesco S, Boscaro C, Trevisi L, Bolego C \& Cignarella A 2018 Estrogen, angiogenesis, immunity and cell metabolism: solving the puzzle. International Journal of Molecular Sciences 19 E859. (https://doi. org/10.3390/ijms19030859)

Tuo W, Harney JP \& Bazer FW 1996 Developmentally regulated expression of interleukin- $1 \beta$ by peri-implantation conceptuses in swine. Journal of Reproductive Immunology 31 185-198. (https://doi.org/10.1016/01650378(96)00975-8)

Waclawik A \& Ziecik A) 2007 Differential expression of prostaglandin (PG) synthesis enzymes in conceptus during peri-implantation period and endometrial expression of carbonyl reductase/PG 9-ketoreductase in the pig. Journal of Endocrinology 194 499-510. (https://doi.org/10.1677/JOE07-0155)

Waclawik A, Jabbour HN, Blitek A \& Ziecik AJ 2009a Estradiol-17beta, prostaglandin E2 (PGE2), and the PGE2 receptor are involved in PGE2 positive feedback loop in the porcine endometrium. Endocrinology 150 3823-3832. (https://doi.org/10.1210/en.2008-1499)

Waclawik A, Blitek A, Kaczmarek MM, Kiewisz J \& Ziecik AJ 2009b Antiluteolytic mechanisms and the establishment of pregnancy in the pig. Society of Reproduction and Fertility Supplement 66 307-320. (https://doi.org/10.1530/biosciprocs.18.0036)

Waclawik A, Kaczmarek MM, Blitek A, Kaczynski P \& Ziecik AJ 2017 Embryo-maternal dialogue during pregnancy establishment and implantation in the pig. Molecular Reproduction and Development 84 842-855. (https://doi.org/10.1002/mrd.22835)

Whitworth KM, Lee K, Benne JA, Beaton BP, Spate LD, Murphy SL, Samuel MS, Mao J, O'Gorman C, Walters EM et al. 2014 Use of the CRISPR/Cas9 system to produce genetically engineered pigs from in vitro-derived oocytes and embryos. Biology of Reproduction 9178. (https://doi.org/10.1095/biolreprod.114.121723)

Whitworth KM, Rowland RR, Ewen CL, Trible BR, Kerrigan MA, CinoOzuna AG, Samuel MS, Lightner JE, McLaren DG, Mileham AJ et al. 2016 Gene-edited pigs are protected from porcine reproductive and respiratory syndrome virus. Nature Biotechnology 34 20-22. (https:// doi.org/10.1038/nbt.3434)

Whitworth KM, Rowland RRR, Petrovan V, Sheahan M, Cino-Ozuna AG, Fang Y, Hesse R, Mileham A, Samuel MS, Wells KD et al. 2019 Resistance to coronavirus infection in amino peptidase $\mathrm{N}$-deficient pigs. Transgenic Research 28 21-32. (https://doi.org/10.1007/s11248018-0100-3)

Whyte JJ, Meyer AE, Spate LD, Benne JA, Cecil R, Samuel MS, Murphy CN, Prather RS \& Geisert RD 2018 Inactivation of porcine interleukin-1 $\beta$ results in failure of rapid conceptus elongation. PNAS 115 307-312. (https://doi.org/10.1073/pnas.1718004115)

Wilson ME, Fahrenkrug SC, Smith TP, Rohrer GA \& Ford SP 2002 Differential expression of cyclooxygenase-2 around the time of elongation in the pig conceptus. Animal Reproduction Science 71 229-237. (https://doi. org/10.1016/s0378-4320(02)00029-5)

Yelich JV, Pomp D \& Geisert RD 1997 Ontogeny of elongation and gene expression in the early developing porcine conceptus. Biology of Reproduction 57 1256-1265. (https://doi.org/10.1095/ biolreprod57.5.1256)

Yoo I, Seo H, Choi Y, Jang H, Han J, Lee S, Choi Y \& Ka H 2019 Analysis of interferon- $\gamma$ receptor IFNGR1 and IFNGR2 expression and regulation at the maternal-conceptus interface and the role of interferon- $\gamma$ on endometrial expression of interferon signaling molecules during early pregnancy in pigs. Molecular Reproduction and Development 86 1993-2004. (https://doi.org/10.1002/mrd.23287)

Yoo I, Kim D, Han J, Lee S, Hong M, Jeon BY, Kim JM \& Ka H 2020 Transcriptomic analysis of interferon- $\gamma$-regulated genes in endometrial explants and their possible role in regulating maternal endometrial immunity during the implantation period in pigs, A true epitheliochorial placentation apecies. Theriogenology 155 114-124. (https://doi. org/10.1016/j.theriogenology.2020.05.045)

Zang YC, Halder JB, Hong J, Rivera VM \& Zhang JZ 2002 Regulatory effects of estriol on $\mathrm{T}$ cell migration and cytokine profile: inhibition of transcription factor NF-kappa B. Journal of Neuroimmunology 124 106-114. (https://doi.org/10.1016/s0165-5728(02)00016-4)

Received 13 November 2020

First decision 24 December 2020

Revised Manuscript received 28 January 2021

Accepted 9 February 2021 